\title{
Author Correction: Solid-phase hetero epitaxial growth of $\alpha$-phase formamidinium perovskite
}

Jin-Wook Lee, Shaun Tan (1), Tae-Hee Han, Rui Wang (1), Lizhi Zhang, Changwon Park, Mina Yoon (D, Chungseok Choi (1), Mingjie Xu, Michael E. Liao (D), Sung-Joon Lee (1D, Selbi Nuryyeva, Chenhui Zhu, Kenny Huynh, Mark S. Goorsky, Yu Huang (1), Xiaoqing Pan (1) \& Yang Yang (1)

Correction to: Nature Communications https://doi.org/10.1038/s41467-020-19237-3, published online 2 November 2020.

The original version of this Article contained an error in the author affiliations.

Mina Yoon was incorrectly associated with Department of Physics and Astronomy, University of Tennessee, Knoxville, TN 37996, USA. The affiliation of Mina Yoon with Center for Nanophase Materials Sciences, Oak Ridge National Laboratory, Oak Ridge, TN, 37831 USA was inadvertently omitted.

This has now been corrected in both the PDF and HTML versions of the Article.

Published online: 12 November 2020

\footnotetext{
(c) (i) Open Access This article is licensed under a Creative Commons Attribution 4.0 International License, which permits use, sharing, adaptation, distribution and reproduction in any medium or format, as long as you give appropriate credit to the original author(s) and the source, provide a link to the Creative Commons license, and indicate if changes were made. The images or other third party material in this article are included in the article's Creative Commons license, unless indicated otherwise in a credit line to the material. If material is not included in the article's Creative Commons license and your intended use is not permitted by statutory regulation or exceeds the permitted use, you will need to obtain permission directly from the copyright holder. To view a copy of this license, visit http://creativecommons.org/licenses/by/4.0/.
}

(C) The Author(s) 2020 